\title{
Watch-wearing as a marker of conscientiousness
}

David A Ellis, Rob Jenkins

Several aspects of an individual's appearance have been shown to predict personality and related behaviour. While some of these cues are grounded in biology (e.g. the human face), other aspects of a person's appearance can be actively controlled (e.g. clothing). In this paper, we consider a common fashion accessory, the wristwatch. In an exploratory sample $(\mathrm{N}>100)$ and a confirmatory sample $(\mathrm{N}>600)$, we compared big-five personality traits between individuals who do or do not regularly wear a standard wristwatch.

Significantly higher levels of conscientiousness were observed in participants who wore a watch. In a third study $(\mathrm{N}=85)$, watch wearers arrived significantly earlier to appointments in comparison to controls. These results are discussed in relation to enclothed cognition and the rise of wearable technology including smartwatches. 
6 David A. Ellis (corresponding author)

7 Department of Psychology

8 Lancaster University

9 Lancaster watch wearers arrived significantly earlier to appointments in comparison to controls. These

\section{Watch-wearing as a marker of conscientiousness}

${ }^{1}$ Department of Psychology, Lancaster University, UK

${ }^{2}$ Department of Psychology, University of York, UK
LA1 4YF
Rob Jenkins

Department of Psychology

University of York

York

YO10 5DD email: DEllis@,lincoln.ac.uk

telephone: +44 (0) 1522886861

\section{Abstract}

Several aspects of an individual's appearance have been shown to predict personality and related behaviour. While some of these cues are grounded in biology (e.g. the human face), other aspects of a person's appearance can be actively controlled (e.g. clothing). In this paper, we consider a common fashion accessory, the wristwatch. In an exploratory sample $(\mathrm{N}>100)$ and a confirmatory sample $(\mathrm{N}>600)$, we compared big-five personality traits between individuals who do or do not regularly wear a standard wristwatch. Significantly higher levels of conscientiousness were observed in participants who wore a watch. In a third study $(\mathrm{N}=85)$, results are discussed in relation to enclothed cognition and the rise of wearable technology including smartwatches. 


\section{Introduction}

The ability to perceive, and generalize from variations in behaviour or appearance helps provide a sense of order and predictability in social interactions (Ambady \& Skowronski 2008). and observers routinely make rapid inferences about personality based on aspects of personal appearance across a variety of contexts (Wall, Taylor, Dixon, Conchie \& Ellis 2013). Inferences are often based on information revealed through cues from the face, body, or voice. For example, aspects of personality extracted from brief snippets of novel voices are remarkably consistent between participants (McAleer, Todorov \& Belin 2014). Similarly, people with broad faces are rated as more aggressive (Carré \& McCormick 2008). For some traits, there appears to be a strong biological basis that explains any behavioural correlate - testosterone affects facial appearance and aggression for example (Verdonch, Gaethofs, Carels \& de Zegher 1999). However, a second related branch of research concerns other aspects of an individuals' appearance that can actively be controlled and a variety of specific inferential links have been observed between particular 'features' of clothing and components of character. Participants who wear glasses were rated as less extraverted and less open to experience (Borkenau 1991; Hellstorm \& Tekle 2006) while the presence of tattoos are associated with lower levels of conscientious and higher levels of extraversion (Swami 2012).

This line of research also raises the question of how reliable these inferences are in terms of predicting behaviour. The fact that these facets of appearance are chosen by the individual rather than being biologically endowed may suggest a weaker link between appearance and behaviour, but a growing body of research on the phenomenon of 'enclothed cognition', where changes in clothing can also effect behaviour challenge this assumption. Adam \& Galinsky (2012) recently 
demonstrated that wearing a lab coat described as a 'doctor's coat' increased sustained attention when compared to wearing a lab coat that was labeled as a 'painter's coat'. They argue that 'enclothed cognition' depends on both the symbolic meaning and the physical experience of wearing clothes. In addition, effects running in the opposite direction (from personality to appearance) may be more plausible for non-biological factors. An aggressive person for instance cannot chose to have a broader face, but he could choose to wear black clothes and make themselves appear more aggressive (Vrij 1997). Here we focus on one particular clothing accessory, the wristwatch. Watches are an interesting case because they are designed to perform a very specific function - to tell the time. This specificity of function lends itself to experimentation because it suggests very targeted predictions about personality and behaviour.

Despite the rise in mobile devices with built-in clocks, the number of standard watch owners has remained static in recent years (Hoffman 2009; Mintel 2010). On the other hand, while many people continue to regularly wear a wristwatch, many chose to avoid them completely. Their prominence or absence in everyday life again makes them an ideal candidate when considering external markers of personality.

While research concerning the relationship between personality and an individual's outward appearance appears to be flourishing (e.g. Hellstrom \& Tekle 2006; Gillath, Bahns, Ge \& Crandall 2012; Swami 2012), a number of limitations continue to affect this literature. First, there remains an over-reliance on university student samples. These samples may not be representative of the wider population (Swami 2012). Secondly, previous research often fails to go beyond self-report (e.g. Gillath etl al 2012), with many papers failing to include an additional 
72 behavioural measure that may help explain or confirm differences observed in personality scores

73 alone.

74 In order to overcome these limitations, and based on the premise that a core component of

75 Conscientiousness is good timekeeping, planning (Back, Schmukle \& Egloff 2006), and

76 organisation (Lee \& Ashton 2004), we predicted that watch wearers would score consistently

77 higher on a simple measure of conscientiousness in comparison to non-watch wearers.

78 Accordingly, timekeeping can be operationalised as punctuality and if watch wearers really are

79 more conscientious then they will, in turn, be more punctual in a real-life setting.

\section{Study 1}

Ethics Statement

The University of Glasgow, College of Science \& Engineering Ethics Committee approved all research (2013-4641). Participants were informed about procedures in detail and provided

86 written informed consent.

\subsubsection{Measures}

90 We assessed personality using The Ten-Item Personality Inventory (TIPI). The TIPI was

91 developed by Gosling, Rentfrow and Swann (2003) to meet the need for a very brief measure of 92 the Big-Five personality dimensions (extraversion, agreeableness, conscientiousness, emotional 93 stability and openness to experience). This measure was chosen due to its short nature, which 
94 allowed us to collect comparable data from both members of the public and students who had a

95 limited amount of time to take part.

\section{$96 \quad$ 2.1.2 Participants}

97 One hundred and twelve participants were recruited and included members of the public 98 attending The British Science Festival in 2010 and students studying psychology at Glasgow or 99 Lincoln Universities in the United Kingdom (62.5\% female) who were waiting to take part in 100 experiments. Their ages ranged from 17-54.

\subsubsection{Procedure}

Individuals approaching a psychology stand were asked if they wished to take part in a short study related to personality. If written consent was obtained, participants were required to fill out the TIPI. They were then asked whether or not they regularly wore a wristwatch. A regular watch wearer was defined as someone who wore a standard wristwatch, most of the time, for at least a year. Finally, all participants were thanked for their time and fully debriefed as to the true nature of the study.

\subsubsection{Results}

109

As expected, participants who identified themselves as regular watch wearers rated themselves as significantly more conscientious when compared with controls (Table I). We also observed that watch wearers scored lower in extraversion, agreeableness and openness, but higher on emotional stability. However, before conducting a further multivariate analysis, we next sought to replicate this finding in a larger confirmatory sample. 


\section{3. Study 2}

118 We attempted to replicate the results from Study 1 in a large online sample who, after 119 completing the TIPI were asked:

'Do you regularly wear a watch?'

121 Participants were recruited via numerous email shots and twitter advertisements. They also 122 provided information about their age, gender, location, working habits and mobile phone 123 ownership. In total, 638 participants took part (48.6\% female). Modal age bands were 35-54 124 (36.4\%) and 18-24 (30.5\%); modal locations UK (60.8\%), North America (13\%). Regarding working habits, $49.7 \%$ confirmed that they worked a traditional Monday-Friday dayshift with the remainder working alternative hours (e.g. shifts, unemployed or students). Finally, 46\% percent

$127(\mathrm{~N}=290)$ identified themselves as being regular watch wearers.

128 $135.410]$

\subsection{Preliminary Analysis}

A primary analysis revealed no significant difference in the distribution of genders between the watch and non-watch groups $\left[\mathrm{X}^{2}(1, \mathrm{~N}=632)=2.36, p=.124\right]$. While $97.48 \%$ of our sample owned a mobile phone, we also observed that there was no significant difference in this distribution of phone ownership between watch and non-watch wearers $\left[\mathrm{X}^{2}(1, \mathrm{~N}=635)=.803, p\right.$ $=.370]$. Finally, there was no significant difference in the distribution of those who worked traditional or shift based work between watch and non-watch groups $\left[\mathrm{X}^{2}(1, \mathrm{~N}=637)=.680, p=\right.$

\subsection{Replication of Study 1}


137 An independent sample t-test again revealed significant differences in mean conscientiousness

138 scores between watch and non-watch wearers (Table II). Further t-tests revealed no other

139 significant personality differences between watch and non-watch wearers across the other four

140 factors of personality $[p$ 's $>.05]$. As observed in Study 1 however, we again observed similar

141 trends whereby watch wearers scored lower in extraversion and openness in comparison to 142 controls.

143

\subsection{Regression Model}

147 In order to confirm that the personality differences reported above hold after controlling for 148 additional factors, we entered age, gender and all five personality factors into a binary logistic 149 model. This model confirms that wearing a watch remains a visible indicator for 150 conscientiousness even after controlling for gender and age (Table III). In other words, the odds 151 of wearing a watch is significantly larger for a person who reports higher levels of 152 conscientiousness (odds ratio $=1.147)$. ---Insert Table III about here---

\section{Multivariate analysis}

157 Personality is a multidimensional construct and effect sizes should also be considered in relation to the overall magnitude of differences observed between two groups. When groups differ along 
159

160

161

162

163

164

165

166

167

168

169

170

171

172

173

174

175

176

177

178

179

180

(69)

several variables at once, the overall between-group difference is not always accurately represented by univariate effect sizes in isolation. Therefore, Del Giudice, Booth \& Irwing (2012) have argued that in order to aggregate differences across variables while also taking correlation patterns into account, it is necessary to computer a multivariate effect size. The Mahalanobis distance $D$ metric allows for these comparisons and is given by the formula:

where $\mathbf{d}$ is the vector of univariate standardised differences (Cohen's $d$ ) and $\mathbf{S}$ is the correlation matrix.

$$
D=\sqrt{d^{\prime} S^{-1} d}
$$
matrix.

We calculated the multivariate generalisation ( $D$ measure) of personality differences in both samples, factoring in changes between the groups across all five factors of personality. When evaluated in this way, personality differences observed in both samples are considerably larger than some of the Cohen's $d$ effect sizes in isolation. The resulting multivariate effect sizes were calculated as $D=.69$ in the exploratory sample and $D=.23$ in the confirmatory sample. While significant differences were observed in levels of conscientiousness between the two groups, the overall differences in personality are not limited to a single personality factor. For example, in both samples watch wearers consistently produce lower extraversion and openness to experience scores.

\section{Study 3}


181 The previous results lend strong support to the notion that people who choose to wear a watch

182 also tend to rate themselves as more conscientious. While organisation is often considered as a

183 lower-order facet score in many personality measures (e.g. as part of the HEXACO Personality

184 Inventory; Lee \& Ashton 2004), higher levels of conscientiousness alone correlate with

185 improved punctuality (Back et al 2006). Ashton (1998) also observed that conscientiousness was

186 negatively associated with self-reported lateness in the workplace. Our final study therefore

187 sought to investigate if punctuality is also related to watch wearing.

188 5.1. Method

189 5.1.1 Participants

190 Ninety participants (29\% male) who arrived to complete a separate experiment in the School of

191 Psychology took part in this study. Their ages ranged from 17 to 48. All participants had 192 previously visited the department on at least one previous occasion. This ensured that 193 participant's were unlikely to become lost before an experiment was scheduled to start.

194 5.1.2 Procedure

195 Participants arriving at the School of Psychology for an unrelated experiment had their exact 196 time of arrival recorded by the experimenter. Time of arrival was recorded as time-lag in minutes 197 between the experiment appointment time and time of each participant's arrival. It was also 198 noted whether they were a regular watch wearer.

199 5.1.3. Results

200 Participants who exceeded an early or late arrival time of +-15 minutes were removed from the 201 analysis $(\mathrm{N}=5)$ to ensure that data were normally distributed. On average, the remaining 202 participants arrived 2.19 minutes before the appointed time $(S D=5.95)$. Mean punctuality scores 
203 (minutes late or early) were calculated for watch and non-watch wearers. A total of 34 watch

204 wearers and 51 non-watch wearers arrival times were analysed (Fig I).

205

206

---Insert Figure I about here---

207

208

An independent sample t-test demonstrated a reliable difference in punctuality with participants

in the watch-wearing group arriving significantly earlier $[M=4.12, S D=5.45]$ in comparison to

210

those who were not wearing a watch $[M=.90, S D=5.96],[t(83)=2.52, p=.01 ; d=.55]$.

\section{General Discussion}

Choosing to wear a watch appears to act as a social marker for an individual who is likely to be more conscientious. A further replication across a larger sample supports this conclusion. We also observed consistent multivariate differences in personality between the two groups with watch wearers showing lower levels of extraversion and openness. Finally, watch wearers behave in way that is consistent with higher levels of conscientiousness by arriving at an appointment earlier than non-watch wearers.

While personality has previously been linked to time perception (e.g. Rammsayer 1997), this is the first study to link personality with the absence or presence of an everyday time cue. Higher levels of conscientiousness have previously been associated with increased levels of selforganisation in a variety of contexts and watch wearing may be an additional purchase decision that interacts with other related individual differences (Aaker 1997). Conscientiousness alone is 
made up of many sub-facets of personality and one of these may play a more important role in watch wearing than others (e.g. organisation, diligence and perfectionism; Lee \& Ashton 2004).

These results could also be considered in the context of enclothed cognition, that is, the influence clothes or fashion accessories can have on a wearer's psychological processes. Adam \& Galinsky (2012) propose that changes in cognition depend on both the symbolic meaning and physical experience of wearing different types of clothes, but this could also apply to wristwatches. As a fashion accessory, or expression of social status the act of wearing a watch may provide an additional, albeit implicit cognitive impact on wearers, which makes them more conscientious and better planners. In terms of punctuality specifically, appointment type may be an important factor to consider in future research, but these results are consistent with research demonstrating that personality is likely to be important when considering punctuality in isolation (Back et al 2006). Even if conscientious individuals are delayed, they will be dutiful enough to try to limit their lateness. In addition, our effect size relating to punctuality is far higher than previous correlations observed between conscientiousness and punctuality in a comparable sample by Back and colleagues (2006).

The standard watch remains technologically simple, but this simplicity explains why countless manufactures of smartwatches are attempting to capitalize on this specific form factor (Fogg 2009). Such devices typically measure and provide additional feedback related to physical and physiological activity (e.g. heart rate). Interestingly, these devices are more likely to be purchased by those who already lead a healthy lifestyle (Swan 2009). The desire to own or wear 
247 a standard wristwatch may therefore be driven by higher levels of conscientiousness in the first

248 instance. Alternatively, the decision to purchase a watch may simply be motivated by a desire to

249 know the time, become more organised and in turn attempt to become more conscientious.

251 Could the act of wearing a watch make an individual healthier or more conscientious? At 252 present, this line of enquiry only extends to more simplistic devices like pedometers, where 253 feedback correlates with an increase in physical activity, but not beyond the duration of the 254 original intervention (Bravata et al 2007). While watch wearing and smartwatch ownership 255 correlate with increased levels of conscientiousness and health promoting behaviours, the 256 direction of these relationships remains unclear, but worthy of further investigation. This is 257 particularly relevant given existing links between the accuracy of clocks and long-term health 258 outcomes (Levine \& Bartlett 1984; Levine \& Norenzayan 1999).

Another future direction for this research would be to explore the effect that watch wearing can

261 have on first impressions and consider the relationship between self and others' perceptions of watch wearing. How such a time cue could influence other evaluative judgments by prompting attributions remains unclear. One might predict that the presence of a watch would serve to help improve an individual's first impression in a specific social context for example, at a job interview (Chapplin, Phillips, Brown, Clanton \& Stein 2000; Dougherty, Turban \& Callender 266 1994). 
268 One limitation which could be levelled at this study is that some participants may own a mobile

269 phone, but not a standard watch, which may act as a confounder because they still have rapid

270 access to the time. However, $100 \%$ of our exploratory sample and $97.48 \%$ in our second sample

271 also owned a mobile phone so this is unlikely to have been an influencing factor. It is worth

272 noting however, that the effect size relating to differences in conscientiousness reduced

273 considerably between our exploratory and confirmatory samples. While the effect size is reduced

274 in our larger sample, small effects could have larger aggregated consequences. For example, the

275 short nature of the personality measure chosen suggests that a larger effect may be observed if a

276 more in-depth measure of personality was deployed, but this may have limited our sample size.

277 For now, we simply wanted to demonstrate that our exploratory findings could be replicated in a

278 further independent sample using an identical measure of personality.

A second limitation concerns the reasons behind watch ownership. While an alternative explanation might conclude that choosing to wear a watch is related to social status and not a desire to know the time, this argument does not chime with the consistency of our results reported here. This is particularly pertinent when considered alongside our behavioural measure however, we cannot rule this additional explanation out completely.

In sum, wearing a device that tells the time on the wrist is likely to remain an important tool for the foreseeable future and to our knowledge this is the first study to demonstrate a link between watch wearing, personality and related behaviour (Anwar 2012). Specifically, watch wearers 
291 data, it is not clear whether being conscientious inclines a person to wear a watch, or whether

292 wearing a watch makes a person more conscientious. Whichever the direction of the relationship,

293 watch wearing is a valid external marker of both personality and associated behaviour.

295 Acknowledgments

We thank Sally Andrews and Lukasz Piwek for helpful comments on an earlier version of this manuscript.

\section{References}

Aaker, J. L. (1997). Dimensions of brand personality. Journal of Marketing Research. 34(3),

347-356. doi: 10.2139/ssrn.945432

302

303

Adam, H., and Galinsky, A. D. (2012). Enclothed cognition. Journal of Experimental Social

Psychology. 48(4), 918-925. doi: 10.1016/j.jesp.2012.02.008

305

306

Ambady, N., \& Skowronski, J. J. (Eds.). (2008). First Impressions. Guilford Press. 
312 Ashton, M. C. (1998). Personality and job performance: The importance of narrow traits. Journal 313 of Organizational Behavior. 19(3), 289-303. doi: 10.1002/(sici)1099-

314 1379(199805)19:3<289::aid-job841>3.3.co;2-3

316 Back, M. D., Schmukle, S. C. and Egloff, B. (2006). Who is late and who is early? Big Five

317 personality factors and punctuality in attending psychological experiments. Journal of Research

318 in Personality. 40, 841-848. doi: 10.1016/j.jrp.2005.11.003

Borkenau, P. (1991). Evidence of a correlation between wearing glasses and personality. Personality and Individual Differences, 12(11), 1125-1128. doi: 10.1016/0191-

$3228869(91) 90074-\mathrm{L}$

Bravata, D. M., Smith-Spangler, C., Sundaram, V., Gienger, A. L., Lin, N., Lewis, R., Stave, C.

D., Olkin, I. and Sirard, J. R. (2007). Using pedometers to increase physical activity and improve health: a systematic review. JAMA. 298 (19), 2296-2304. doi: 10.1001/jama.298.19.2296

328 Carré, J. M. and McCormick, C. M. (2008). In your face: facial metrics predict aggressive behaviour in the laboratory and in varsity and professional hockey players. Proceedings of the

330 Royal Society of London B: Biological Sciences,275(1651), 2651-2656. doi:

$331 \quad 10.1098 / \mathrm{rspb} .2008 .0873$ 
333 Chapplin, W. F., Phillips, J. B., Brown, J. D., Clanton, N. R. and Stein, J. I. (2000).

334 Handshaking, gender, personality, and first Impressions. Journal of Personality and Social

335 Psychology. 79(1), 110-117. doi: 10.1037//0022-3514.79.1.110

336

Dougherty, T. W., Turban, D. B. and Callender, J. C. (1994). Confirming first impressions in the employment interview: A field study of interviewer behavior. Journal of Applied Psychology. 79(5), 659-665. doi: 10.1037//0021-9010.79.5.659

341 Fogg, B. J. (2009). A behavior model for persuasive design. In Proceedings of the 4th

342 international Conference on Persuasive Technology (p. 40). ACM. doi: $10.1145 / 1541948.1541999$

Gillath, O. Bahns, A. J., Ge, F. and Crandall, C. S. (2012). Shoes as a source of first impressions. Journal of Research in Personality. 46(4), 423-430. doi: 10.1016/j.jrp.2012.04.003

349 Gosling, S. D., Rentfrow, P. J., and Swann, W. B., Jr. (2003). A very brief measure of the big 350 five personality domains. Journal of Research in Personality. 37, 504-528. doi: 10.1016/s00926566(03)00046-1 
353 Hellstrom, A. and Tekle, J. (2006). Person perception through facial photographs: Effects of

354 glasses, hair and beard on judgments of occupation and personal qualities. European Journal of

355 Social Psychology. 24(6), 693-705. doi: 10.1002/ejsp.2420240606

356

357 Hoffman, E. (2009). Time. Profile Books Ltd.

358

359

Kline, P. (2000). Handbook of Psychological Testing. London, Routledge. doi:

360

$10.4324 / 9781315812274$

361

362

McAleer P, Todorov A. and Belin P. (2014). How do you say 'Hello’? Personality impressions

363

from brief novel voices. PLoS ONE 9(3): e90779. doi:10.1371/journal.pone.0090779

364

365

Mintel. (2010, October 27). Is time ticking for the watch? Retrived from:

366

http://www.mintel.com/press-centre/press-releases/615/is-time-ticking-for-the-watch-one-in-

367 seven-brits-claim-they-have-no-reason-to-wear-one.

368

369 Lee, K., \& Ashton, M. C. (2004). Psychometric properties of the HEXACO Personality

370 Inventory. Multivariate Behavioral Research. 39(2), 329-358. doi:

$37110.1207 / \mathrm{s} 15327906 \mathrm{mbr3902 \_ 8}$ 
373 Levine, R. V. and Bartlett, K. (1984). Pace of life, punctuality, and coronary heart disease in six

374 countries. Journal of Cross-Cultural Psychology. 15 (2), 233-255. doi: $375 \quad 10.1177 / 0022002184015002009$

376

377 Levine, R. V. and Norenzayan, A. (1999). The pace of life in 31 countries. Journal of Cross378 cultural Psychology. 30 (2), 178-205. doi: 10.1177/0022022199030002003

Swami, V. (2012). Written on the body? Individual differences between British adults who do and do not obtain a first tattoo. Scandinavian Journal of Psychology. 53, 407-412. doi: $10.1111 / \mathrm{j} .1467-9450.2012 .00960 . x$

Swan, M. (2009). Emerging patient-driven health care models: an examination of health social networks, consumer personalized medicine and quantified self-tracking. International Journal of Environmental Research and Public Health. 6(2), 492-525. doi: 10.3390/ijerph6020492 treatment on craniofacial growth in boys with delayed puberty. European Journal of 
391 Vrij, A. (1997). Wearing black clothes: The impact of offenders' and suspects' clothing on

392 impression formation. Applied Cognitive Psychology, 11(1), 47-53. doi: 10.1002/(sici)1099-

393 0720(199702)11:1<47::aid-acp421>3.3.co;2-8

394

395 Wall, H. J., Taylor, P. J., Dixon, J., Conchie, S. M., \& Ellis, D. A. (2013). Rich contexts do not

396 always enrich the accuracy of personality judgments. Journal of Experimental Social

397 Psychology, 49(6), 1190-1195. doi: 10.1016/j.jesp.2013.05.010

398

399 Wood, S. A. and Hampson, S.E. (2005). Measuring the Big Five with single items using a

400 bipolar response scale. European Journal of Personality. 19, 373-390. doi: 10.1002/per.542 


\section{Table $\mathbf{1}$ (on next page)}

Personality differences between watch and non-watch wearers in an exploratory sample Note: $*=p<.05$. Standard Deviations appear in parenthesis alongside means. 
2 Table I. Personality differences between watch and non-watch wearers in an exploratory sample

Exploratory Sample $\mathrm{N}=112$

\begin{tabular}{|c|c|c|c|c|c|}
\hline & \multirow[b]{2}{*}{$\alpha$} & \multicolumn{2}{|c|}{ Watch } & \multirow[b]{2}{*}{$t$} & \multirow[b]{2}{*}{$d$} \\
\hline & & $\begin{array}{c}\text { yes } \\
n=53\end{array}$ & $\begin{array}{c}\text { no } \\
\mathrm{n}=59\end{array}$ & & \\
\hline Extraversion & .48 & $4.53(1.17)$ & $4.69(1.30)$ & .67 & -.13 \\
\hline Agreeableness & .13 & $4.49(1.32)$ & $4.73(.88)$ & 1.13 & -.22 \\
\hline Conscientiousness & .63 & $5.35(1.54)$ & $4.31(1.24)$ & $3.94^{*}$ & .75 \\
\hline Emotional Stability & .45 & $4.65(1.31)$ & $4.57(1.21)$ & .35 & .07 \\
\hline Openness to Experiences & .39 & $5.18(1.26)$ & $5.46(.98)$ & 1.31 & -.25 \\
\hline
\end{tabular}

3 Note: $*=p<.05$. Standard Deviations appear in parenthesis alongside means.

4

5 
Table 2 (on next page)

Personality differences between watch and non-watch wearers in a confirmatory sample

**The TIPI was intentionally designed to produce low coefficient alphas, which are themselves misleading when calculated on scales with a reduced number of items (Kline 2000; Wood \& Hampson 2005). Our reported values compare favorably to the internal measures of consistency observed by Gosling et al (2003) during the scales initial development. 
1 Table II. Personality differences between watch and non-watch wearers in a confirmatory sample Confirmatory Sample N=638

\begin{tabular}{lccccc}
\hline & & \multicolumn{3}{c}{ Watch } & \\
\cline { 2 - 4 } & $\alpha^{* *}$ & $\mathrm{n}=290$ & $\mathrm{n}=348$ & $t$ & $d$ \\
\hline Extraversion & .77 & $3.83(1.57)$ & $3.90(1.60)$ & .55 & -.04 \\
Agreeableness & .36 & $4.71(1.20)$ & $4.64(1.22)$ & .80 & .06 \\
Conscientiousness & .58 & $4.81(1.39)$ & $4.56(1.37)$ & $2.21^{*}$ & .18 \\
Emotional Stability & .66 & $4.53(1.48)$ & $4.57(1.46)$ & .33 & -.03 \\
Openness to Experiences & .41 & $5.14(1.15)$ & $5.32(1.15)$ & 1.89 & -.01 \\
\hline
\end{tabular}

2 Notes. ${ }^{*}=p<.05$. Standard Deviations appear in parenthesis alongside means.

3 **The TIPI was intentionally designed to produce low coefficient alphas, which are themselves

4 misleading when calculated on scales with a reduced number of items (Kline 2000; Wood \&

5 Hampson 2005). Our reported values compare favorably to the internal measures of consistency

6 observed by Gosling et al (2003) during the scales initial development. 
Table 3 (on next page)

Results from a binary logistic model $\left[\mathrm{X}^{2}\left(9, \mathrm{~N}=617^{*}\right)=20.51, p=.015\right]$. This controls for a number of other variables that may also predict watch wearing.

Notes: ${ }^{*}=617$ (22 participants from the original sample did not confirm their age and/or gender). **Significant $\mathrm{p}$-values are highlighted in bold. 
1

Differences in arrival times between watch and non-watch wearers.

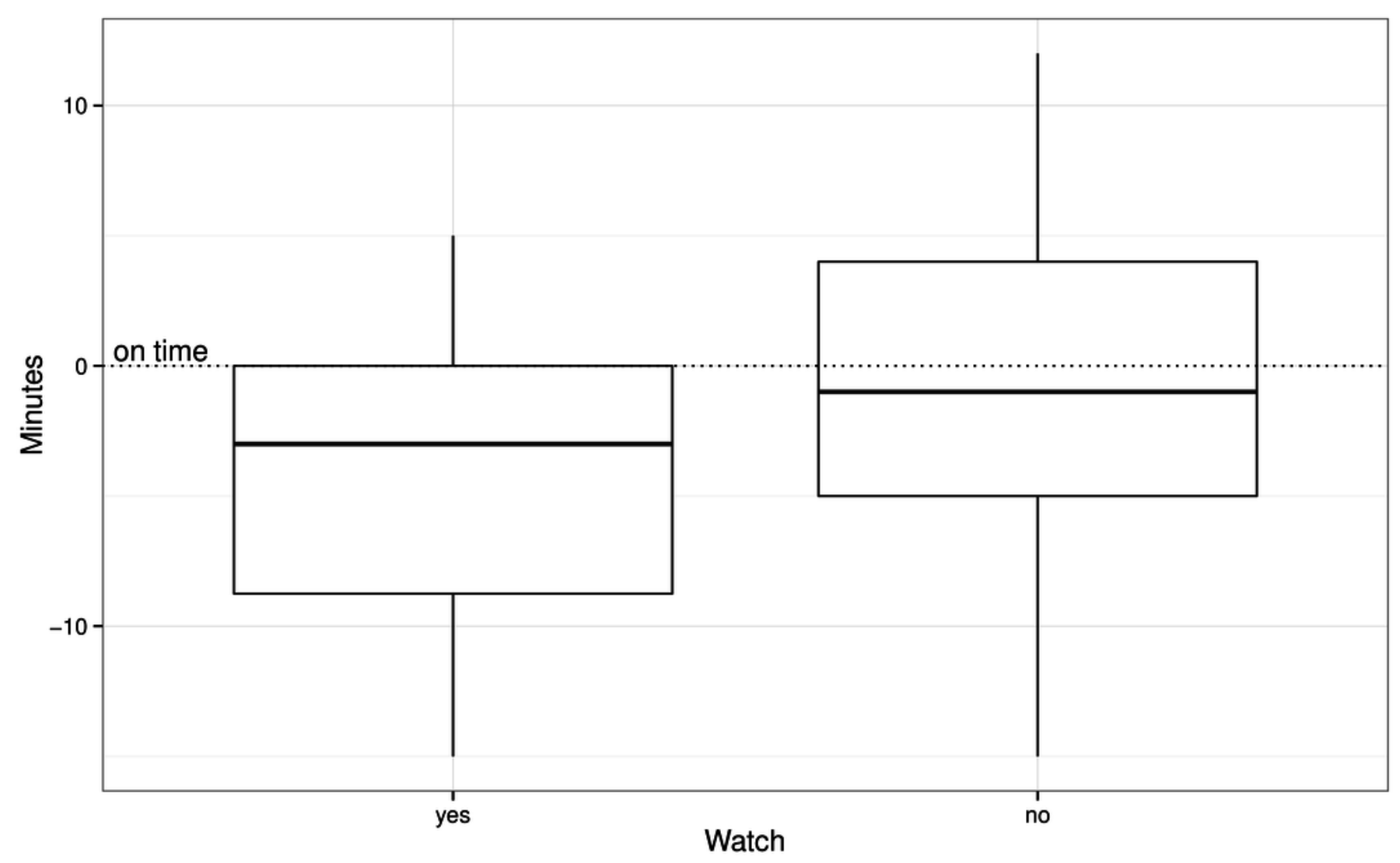

